\title{
Extraction of Illegal Dyes from Red Chili Peppers with Cholinium-Based Deep Eutectic Solvents
}

\author{
Shuqiang Zhu, ${ }^{1,2}$ Dongling Liu, ${ }^{3}$ Xinyue $\mathrm{Zhu},{ }^{1}$ Along Su, ${ }^{2}$ and Haixia Zhang \\ ${ }^{1}$ Key Laboratory of Nonferrous Metal Chemistry and Resources Utilization of Gansu Province and College of \\ Chemistry and Chemical Engineering, Lanzhou University, Lanzhou 730000, China \\ ${ }^{2}$ Gansu Food Inspection and Research Institute, Lanzhou 730030, China \\ ${ }^{3}$ Gansu Key Laboratory of Traditional Chinese Medicine Quality and Standard, Gansu University of Chinese Medicine, \\ Lanzhou 730000, China \\ Correspondence should be addressed to Haixia Zhang; zhanghx@lzu.edu.cn
}

Received 5 February 2017; Revised 13 June 2017; Accepted 5 July 2017; Published 31 July 2017

Academic Editor: Marek Trojanowicz

Copyright (C) 2017 Shuqiang Zhu et al. This is an open access article distributed under the Creative Commons Attribution License, which permits unrestricted use, distribution, and reproduction in any medium, provided the original work is properly cited.

\begin{abstract}
Deep eutectic solvents (DESs) as a new kind of green solvents have been used to extract bioactive compounds but there are few applications in extracting chrysoidine dyes. In this study, we developed an ultrasonic-assisted extraction method with choline chloride/hydrogen bond donor (ChCl/HBD) DES for the extraction of chrysoidine G (COG), astrazon orange G (AOG), and astrazon orange R (AOR) in food samples. Some experimental parameters, such as extraction time, raw material/solvent ratio, and temperature, were evaluated and optimized as follows: the ratio of $\mathrm{ChCl} / \mathrm{HBD}, 1: 2(\mathrm{v} / \mathrm{v})$; the ratio of sample/DES, $1: 10(\mathrm{~g} / \mathrm{mL})$; extraction time, $20 \mathrm{~min}$; extraction temperature, $50^{\circ} \mathrm{C}$. Under the optimized conditions, the limits of detection $(\mu \mathrm{g} / \mathrm{mL}) \mathrm{were} 0.10$ for COG and 0.06 for AOG and AOR. The relative standard deviations were in the range of $1.2-2.1 \%$. The recoveries of the three dyes were in the range of $80.2-105.0 \%$. By comparing with other commonly used solvents for extracting chrysoidine dyes, the advantages of DESs proved them to be potential extraction solvents for chrysoidine G, astrazon orange G, and astrazon orange R in foods.
\end{abstract}

\section{Introduction}

Food colorants are often added to improve color appearance and to promote sales in food [1]. As an attractive group of food additives, their use range and dosage are restricted strictly in many countries. In China, the use of synthetic colorants in foods is strictly controlled by Directive GB 2760-2014 [2] of the Ministry of Health [3]. In recent years, although natural food colorants have become more and more popular with consumer, synthetic colorants are still used illegally due to their low costs, high effectiveness, and good stability in many foods $[4,5]$. Chrysoidine, a type of industrial azoic dye, is a kind of illegal additive banned in China $[2,6,7]$ which could cause acute and chronic toxicity to mammals administrated by oral or skin route or inhaled [8] and has been confirmed to be genotoxic, mutagenic, and carcinogenic [9-11]. Unfortunately, chrysoidine has been reported in some red hot chili peppers in China [12].
Several analytical methods for the determination of dyes have been proposed, including high performance liquid chromatography UV (HPLC-UV) [13], liquid chromatography coupled to mass spectrometry (LC-MS) [14, 15], and enzyme linked immunosorbent assay (ELISA) with newly developed polyclonal antibodies [16]. In all the analytical methods, conventional organic solvents such as chloroform and ethyl acetate are widely used in the extraction of chrysoidine dyes from food samples.

To overcome the limitations of toxicity of organic solvents, deep eutectic solvents (DESs), as a new kind of green solvents, have emerged [17]. DES is generally composed of two or three nontoxic components, forming eutectic mixture with a much lower melting point than either of the individual components [18]. In general, one of the components is choline chloride $(\mathrm{ChCl})$ and another component is hydrogen bond donor (HBD) containing functional groups of carboxylic acids, urea, or polyols $[19,20]$. There have been a great 
TABLE 1: DESs synthesized in the work.

\begin{tabular}{lccc}
\hline Product & Salt & HBD & $\begin{array}{c}\text { Mole ratio } \\
(\mathrm{ChCl}: \mathrm{HBD})\end{array}$ \\
\hline DES1 & $\mathrm{ChCl}$ & Ethyl glycol & $1: 3$ \\
DES2 & $\mathrm{ChCl}$ & 1,2-Butanediol & $1: 3$ \\
DES3 & $\mathrm{ChCl}$ & Glycerol & $1: 3$ \\
DES4 & $\mathrm{ChCl}$ & 1,3-Butanediol & $1: 3$ \\
DES5 & $\mathrm{ChCl}$ & 1,4-Butanediol & $1: 3$ \\
\hline
\end{tabular}

number of studies on dissolution and separation in using DESs, such as $\mathrm{CO}_{2}$ solubility [21], dissolution of metal oxides [22] and drug [23], and purification of biodiesel [24]. DESs are capable of donating or accepting electrons or protons to form hydrogen bonds, which gives them excellent dissolution properties and potential for extraction $[18,25]$. Up to now, no one has reported the application of DES for the extraction of COG, AOG, and AOR in food samples.

In this study, a series of DESs mixing $\mathrm{ChCl}$ and HBDs at different ratios were used to extract COG, AOG, and AOR from red hot chili peppers. Using the optimal system composition, other experimental parameters such as sample ratio, ultrasonic power, temperature, and time were optimized systematically. HPLC with UV detector was chosen as an analytical apparatus.

\section{Methods and Materials}

2.1. Chemicals and Materials. COG, AOG, and AOR (98\%) were obtained from Sigma (St. Louis, MO, USA). $\mathrm{ChCl}$ $(>98.0 \%)$, ethylene glycol (>99.0\%), glycerol (>99.0\%), 1,2-butanediol (>98.0\%), 1,3-butanediol (>99.0\%), and 1,4-butanediol $(>99.0 \%)$ were purchased from Sinopharm Chemical Reagent Co. Ltd. (Shanghai, China). Methanol and acetonitrile of HPLC grade were supplied by Merck Chemical Co. Ltd. (Darmstadt, Germany). All the other solvents used in the experiment were of analytical grade. Ultrapure water was obtained from the Milli-Q system (Millipore, Bedford, MA, USA). All the samples were passed through a filter (Nylon, $0.45 \mu \mathrm{m}, \mathrm{MN}$, Germany) before HPLC-UV analysis.

2.2. Preparation of DES. DESs were prepared by heating $\mathrm{ChCl}$ and $\mathrm{HBDs}$ to $80^{\circ} \mathrm{C}$ with constant stirring until a homogeneous liquid was formed. $\mathrm{ChCl}$ was mixed with each HBD at the molar ratios $(1: 3)$, as shown in Table 1.

2.3. Extraction Procedure. Dried red hot chili peppers powder $(0.10 \mathrm{~g})$ was spiked with $5 \mu \mathrm{g}$ of COG, AOG, and AOR, respectively, and was extracted with $1.0 \mathrm{~mL}$ of the DES by the help of ultrasonic irradiation $(75 \mathrm{~W}, 20 \mathrm{~min})$. The turbid solutions obtained were centrifuged at $12,000 \mathrm{rpm}$ for $5 \mathrm{~min}$. The supernatant $(500 \mu \mathrm{L})$ was mixed with an equal volume of methanol and filtered $(0.45 \mu \mathrm{m})$ before being analyzed by HPLC-UV. Each group experiment was repeated three times.

2.4. HPLC Instrumentation. A Waters e2695 four-solvent gradient pump and a Waters UV2487 detector (Waters Co.,

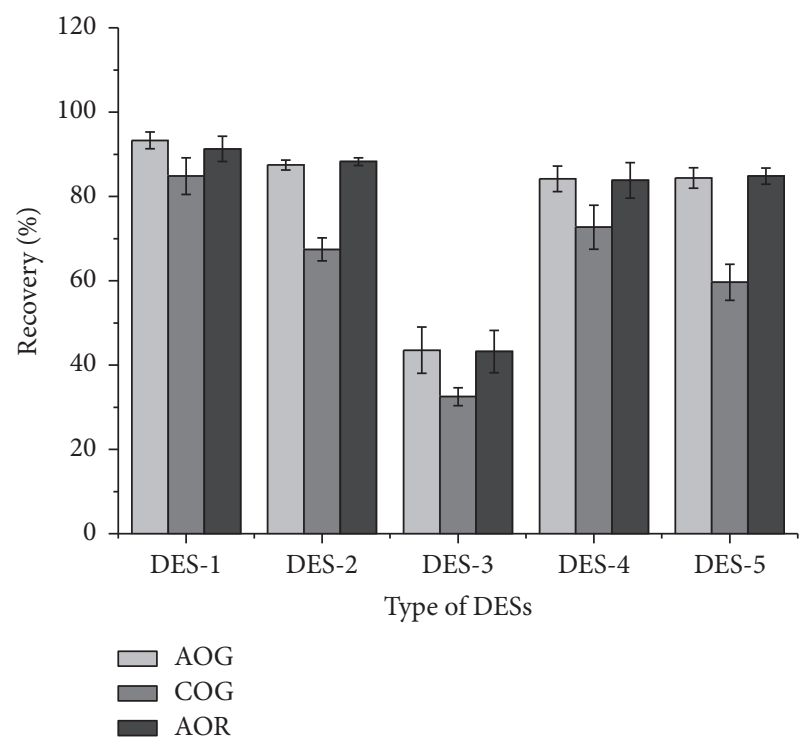

FIGURE 1: Effect of different type of DES on the recoveries of COG, AOG, and AOR. Molar ratio of $\mathrm{ChCl}$ to $\mathrm{HBD}$ : 1/3, sample/liquid: $0.1 \mathrm{~g} / \mathrm{mL}$, temperature: $30.0^{\circ} \mathrm{C}$, time: $20 \mathrm{~min}$, and ultrasonic power: $75 \mathrm{~W}$.

USA) were used for HPLC-UV analysis. Separations were done using an ODS- $\mathrm{C}_{18}$ column $(250 \mathrm{~mm} \times 4.6 \mathrm{~mm}$ i.d., $5 \mu \mathrm{m}$, Krosmail Co., Sweden). The mobile phase, methanol and $10 \mathrm{mmol} / \mathrm{L}$ of ammonium acetate aqueous solution $(70: 30, \mathrm{v} / \mathrm{v})$, was used as the isocratic elution at room temperature. The flow-rate, UV wavelength, and injection volume were set to $1.0 \mathrm{~mL} / \mathrm{min}, 485 \mathrm{~nm}$, and $10.0 \mu \mathrm{L}$, respectively.

\section{Results and Discussion}

3.1. Selection of DESs. The choice of extraction method and type of DESs were very important for extracting COG, AOG, and AOR from red hot chili peppers. As shown in Figure 1, the recovery of COG, AOG, and AOR extracted using DES-1 was optimum compared to the other DESs. Except DES-3, the other DESs offered similar recovery results for AOG and AOR. COG recovery was affected the most by the different kinds of HBD. Glycerol (in DES-3) was not found to be a suitable HBD for the extraction of these dyes. The three hydroxyl groups in the glycerol molecule exhibit stereospecific blockades with each other, which was not beneficial to forming of hydrogen bonds with the dyes.

The physicochemical properties, such as viscosity, surface tension, and polarity, have a significant effect on the extraction efficiency of DES. The viscosity and surface tension of DES-1 are the lowest among the five DESs tested and the polarity is relatively high [19]. The low viscosity of DES brings about high diffusivity $[26,27]$ which can improve the extraction efficiency of the three dyes. In consideration of similarity-intermiscibility theory, the polarity of DES-1 appears to be more similar to those of AOR $(\log$ P 6.82) and AOG $(\log P$ 5.14) than those of COG $(\log P$ 2.71, calculated by Discovery Studios), which is responsible for its high 


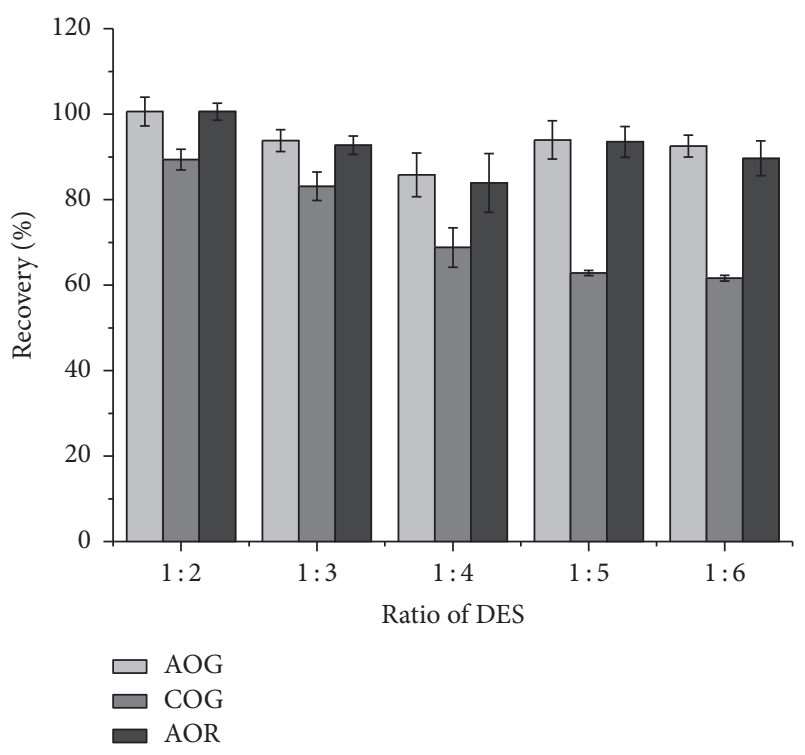

FIGURE 2: Effects of $\mathrm{ChCl} / \mathrm{HBD}$ molar ratios on the recoveries of dyes. Sample/liquid: $0.1 \mathrm{~g} / \mathrm{mL}$, temperature: $30.0^{\circ} \mathrm{C}$, time: $20 \mathrm{~min}$, and ultrasonic power: $75 \mathrm{~W}$.

extractability. However, the extraction efficiency of DES-3 was much lower than that of other DESs because of its high viscosity and surface tension.

\subsection{Effect of $\mathrm{ChCl} / \mathrm{HBD}$ Molar Ratio. Different $\mathrm{ChCl} / \mathrm{HBD}$} ratios $(1: 2,1: 3,1: 4,1: 5$, and $1: 6)$ in DES of $\mathrm{ChCl}$ and ethyl glycol (DES-1) were evaluated. As shown in Figure 2, the AOG and AOR were almost entirely extracted in the DES with different ratios except in the DES of $1: 4$. The recovery of COG decreased with the increasing of ethyl glycol in DES. Finally the DES with the ratio of $1: 2$ was chosen for the further experiments, named DES-1-2.

To confirm the extraction efficiency of DES-1-2, several organic solvents such as ethylene glycol (EG), methanol $(\mathrm{MEOH})$, and ethanol $(\mathrm{ETOH})$ were applied to extract the three dyes. As shown in Figure 3, although the recoveries of both AOG and AOR extracted by DES-1-2 and the three organic solvents ran up to $93 \%$, the recovery of COG extracted by DES-1-2 was the highest.

3.3. Effect of Sample/Liquid Ratio. The sample/DES-1-2 ratio was explored. A range of sample/liquid ratios $(1: 5,1: 10$, $1: 15,1: 20$, and $1: 25,(\mathrm{~g} / \mathrm{mL}))$ were adopted to achieve the optimum ratios. As shown in Figure 4, the recoveries of the COG, AOG, and AOR were within 83.7 to $101.4 \%$, when the sample/liquid ratio was $1: 10$ or $1: 5$. However, the higher sample/liquid ratio than $1 / 10(\mathrm{~g} / \mathrm{mL})$ did not significantly affect the recoveries of the COG and AOG, whereas the recoveries of the AOR decreased. Finally, the sample/liquid ratio $1 / 10$ was chosen because the ratio $1 / 5$ resulted in much less liquid to operate.

3.4. Effect of Temperature. Temperature can affect the physicochemical properties of DES, so its effect on the extraction was studied. Generally, high temperatures were accompanied

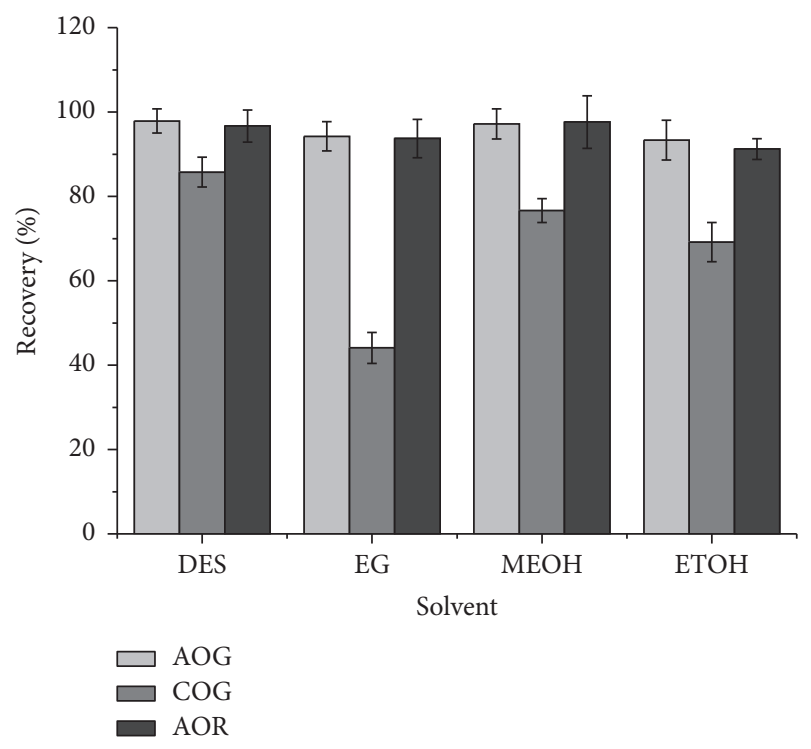

FIGURE 3: Effect of different solvents on the recoveries of dyes. DES: DES-1-2, sample/liquid: $0.1 \mathrm{~g} / \mathrm{mL}$, temperature: $30^{\circ} \mathrm{C}$, time: $20 \mathrm{~min}$, and ultrasonic power: $75 \mathrm{~W}$.

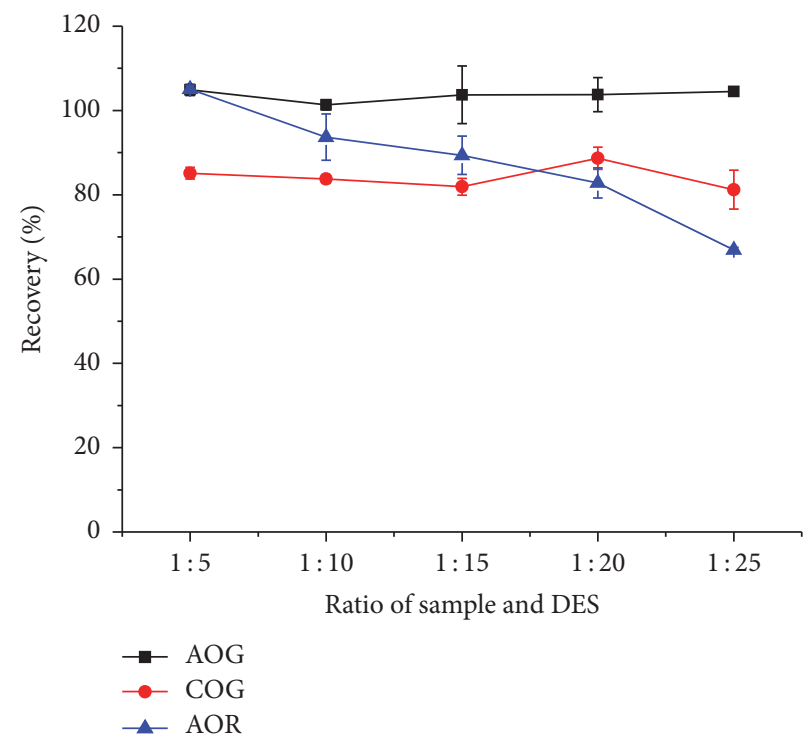

FIGURE 4: Effect of ratio of sample/DES-1-2 on the recoveries of COG, AOG, and AOR. Temperature: $30^{\circ} \mathrm{C}$, time: $20 \mathrm{~min}$, and ultrasonic power: $75 \mathrm{~W}$.

with lower viscosity and surface tension. As shown in Figure 5 , the recoveries of the dyes gently increased until the temperature increased to $50^{\circ} \mathrm{C}$, but there was a little decrease when the temperature was above $50^{\circ} \mathrm{C}$. Therefore, $50^{\circ} \mathrm{C}$ was selected as the appropriate temperature.

3.5. Effect of Extraction Time. The ultrasonic time from 15 to $50 \mathrm{~min}$ was also optimized for the extraction of these dyes. In Figure 6, the largest recoveries of AOG and AOR were achieved after being treated for $20 \mathrm{~min}$ and underwent no change even for longer time. For COG, a period longer than 
TABLE 2: Parameters of analytical performance of the proposed method $(n=3)$.

\begin{tabular}{|c|c|c|c|c|c|c|c|}
\hline Analyte & $R^{2}$ & $\begin{array}{c}\text { RSD } \\
(\%)\end{array}$ & $\begin{array}{c}\text { Spiked } \\
(\mu \mathrm{g})\end{array}$ & Detected $(\mu \mathrm{g})$ & $\begin{array}{c}\text { Recovery } \\
(\%)\end{array}$ & $\begin{array}{c}\text { LOD } \\
(\mu \mathrm{g} / \mathrm{mL})\end{array}$ & $\begin{array}{c}\text { LOQ } \\
(\mu \mathrm{g} / \mathrm{mL})\end{array}$ \\
\hline \multirow{3}{*}{ AOG } & \multirow{3}{*}{0.9997} & \multirow{3}{*}{1.2} & 0.5 & 0.46 & $91.5 \pm 4.2$ & \multirow{3}{*}{0.06} & \multirow{3}{*}{0.21} \\
\hline & & & 5.0 & 4.71 & $94.3 \pm 2.6$ & & \\
\hline & & & 10.0 & 10.51 & $105.0 \pm 1.2$ & & \\
\hline \multirow{3}{*}{ COG } & \multirow{3}{*}{0.9998} & \multirow{3}{*}{2.1} & 0.5 & 0.40 & $80.2 \pm 3.1$ & \multirow{3}{*}{0.10} & \multirow{3}{*}{0.33} \\
\hline & & & 5.0 & 4.26 & $85.2 \pm 2.8$ & & \\
\hline & & & 10.0 & 9.20 & $92.0 \pm 1.9$ & & \\
\hline \multirow{3}{*}{ AOR } & \multirow{3}{*}{0.9998} & \multirow{3}{*}{1.3} & 0.5 & 0.43 & $86.8 \pm 3.4$ & \multirow{3}{*}{0.06} & \multirow{3}{*}{0.29} \\
\hline & & & 5.0 & 4.68 & $93.6 \pm 1.8$ & & \\
\hline & & & 10.0 & 10.0 & $100.0 \pm 2.3$ & & \\
\hline
\end{tabular}

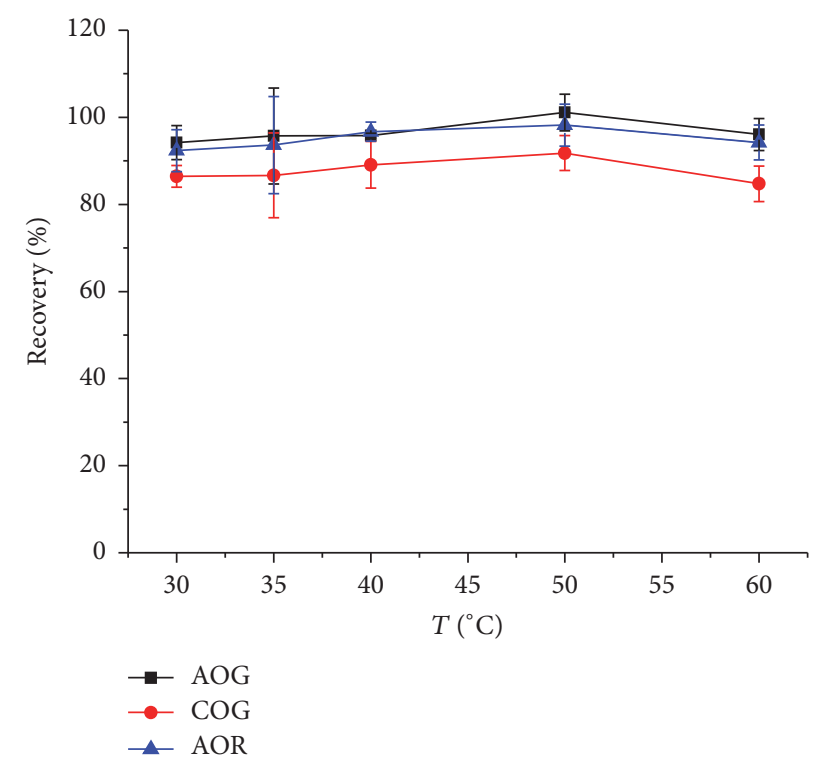

FIgURE 5: Effect of temperature on the recoveries of dyes. Sample/DES-1-2: $0.1 \mathrm{~g} / \mathrm{mL}$, time: $20 \mathrm{~min}$, and ultrasonic power: $75 \mathrm{~W}$.

$30 \mathrm{~min}$ was no help to the extraction. Hence $20 \mathrm{~min}$ was adopted.

3.6. Validation of the Proposed Method. The optimum conditions of ChCl-based DES-1-2 as extractant in our experiments were as follows: the ratio of $\mathrm{ChCl} / \mathrm{HBD}, 1: 2$; sample/DES1-2 ratio, 1:10 (g/mL); extraction time, $20 \mathrm{~min}$; extraction temperature, $50^{\circ} \mathrm{C}$. Under the above conditions, we tested the linearity, precision, detection limits, and other characteristics for the method (Table 2). A series of the three dyes with different concentrations in the range of $0.5-20.0 \mu \mathrm{g} / \mathrm{mL}$ were prepared to make calibration curves with correlation coefficients larger than 0.9997 . The precision tests were done by carrying out five parallel experiments for each compound: the relative standard deviation (RSD) values, the limit of detection (LOD) values based on the chromatographic signal to the baseline noise ratio $(S / N=3)$, and the limit of quantification (LOQ) based on $S / N=10$. Figure 7 showed the chromatograms of the blank red hot chili peppers (curve

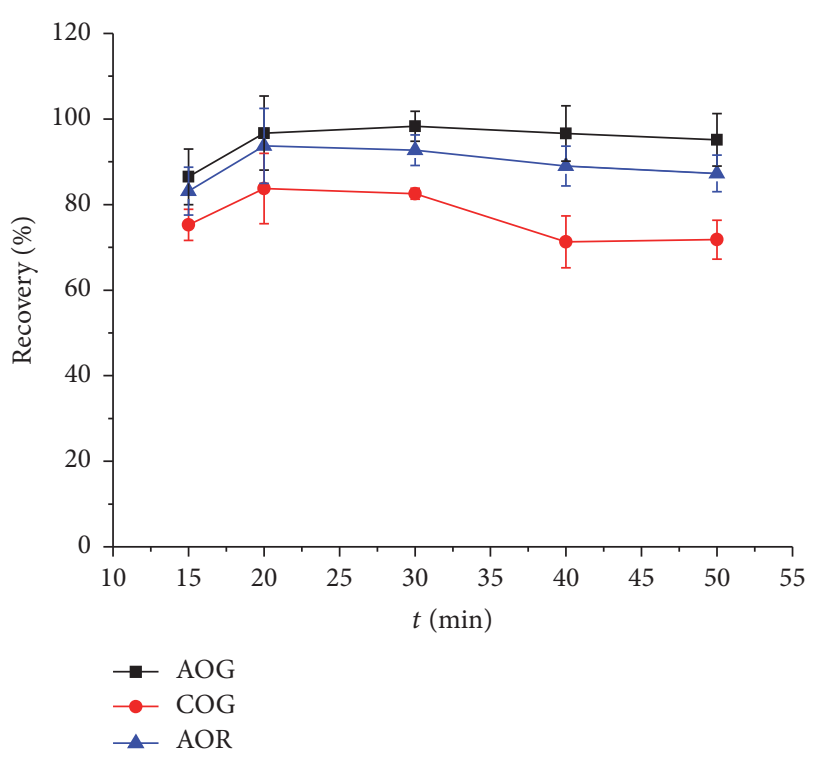

FIGURE 6: Effect of extraction time on the recoveries of the three dyes. Sample/DES-1-2: $0.1 \mathrm{~g} / \mathrm{mL}$, temperature: $50.0^{\circ} \mathrm{C}$, and ultrasonic power: $75 \mathrm{~W}$.

$1)$, the standards $(2 \mu \mathrm{g} / \mathrm{mL}$, curve 2$)$, and the red hot chili peppers spiked standard solution $(2.5 \mu \mathrm{g} / \mathrm{mL}$, curve 3$)$.

3.7. Application. The optimized method was used to determine the target compounds in different foods (red hot chili peppers, Chinese red peppers, and bean curd stick) from a local market. No dyes were found. Then the dyes were added to the samples and the recoveries were calculated, as shown in Table 3. The experimental results confirmed that the method was validated for the determination of COG, AOG, and AOR in real samples.

\section{Conclusions}

In this work, we developed a green and efficient extraction method, involving ultrasonic-assisted extraction of food samples with $\mathrm{ChCl} /$ Ethyl glycol $(1: 2)$ DES for the extraction of COG, AOG, and AOR. The experimental results showed the DES as extractant could offer the satisfying recovery with 
TABLE 3: Recoveries of the dyes in different food samples with this method $(n=3)$.

\begin{tabular}{lcccr}
\hline Products & Compounds & $\begin{array}{c}\text { Spiked } \\
(\mu \mathrm{g})\end{array}$ & $\begin{array}{c}\text { Detected } \\
(\mu \mathrm{g})\end{array}$ & Recovery $(\%)$ \\
\hline \multirow{3}{*}{ Red hot chili peppers } & AOG & & 2.4 & $95.6 \pm 2.7$ \\
& COG & 2.5 & 2.2 & $90.0 \pm 1.3$ \\
& AOR & & 2.3 & $91.2 \pm 4.4$ \\
Chinese red peppers & AOG & & 2.3 & $91.2 \pm 2.3$ \\
& COG & 2.5 & 2.4 & $96.0 \pm 2.5$ \\
Bean curd stick & AOR & & 2.3 & $90.4 \pm 2.7$ \\
& AOG & 2.5 & 2.5 & $100.8 \pm 1.1$ \\
& COG & & 2.4 & $97.6 \pm 0.4$ \\
\hline
\end{tabular}

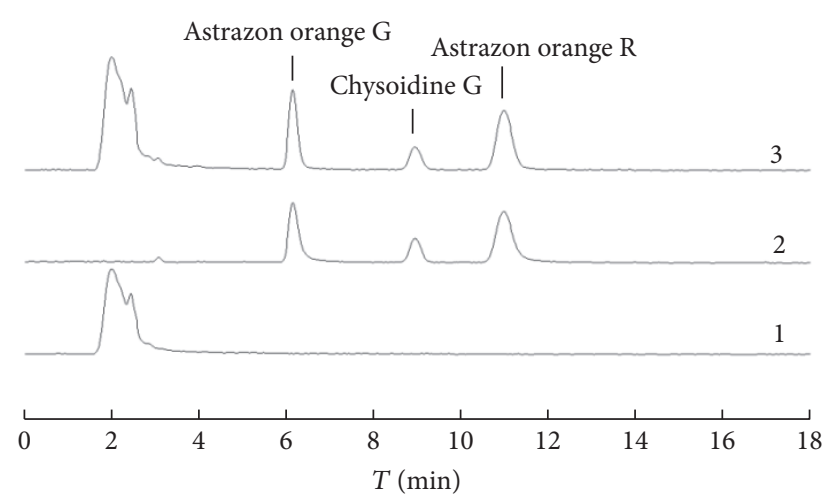

FIGURE 7: Chromatograms of the red hot chili peppers (curve 1), the standard of three dyes (each $2 \mu \mathrm{g} / \mathrm{mL}$, curve 2 ), and the red hot chili peppers spiked standard solution (each $2.5 \mu \mathrm{g} / \mathrm{mL}$, curve 3 ).

less organic solvent consumed with the simple operation. The method could be used successfully for the analysis of illegal additive dyes (COG, AOG, and AOR) in solid food.

\section{Conflicts of Interest}

The authors declare that there are no conflicts of interest.

\section{Acknowledgments}

The authors thank the National Science Foundation of China (21375052).

\section{References}

[1] H.-Y. Huang, Y.-C. Shih, and Y.-C. Chen, "Determining eight colorants in milk beverages by capillary electrophoresis," Journal of Chromatography A, vol. 959, no. 1-2, pp. 317-325, 2002.

[2] Food Additive Usage: Healthy Criterion of People's Republic of China, GB 2760, 2014.

[3] H. Sun, N. Sun, H. Li, J. Zhang, and Y. Yang, "Development of Multiresidue Analysis for 21 Synthetic Colorants in Meat by Microwave-Assisted Extraction-Solid-Phase Extraction-Reversed-Phase Ultrahigh Performance Liquid Chromatography," Food Analytical Methods, vol. 6, no. 5, pp. 1291-1299, 2013.
[4] R. Noguerol-Cal, J. M. López-Vilariño, M. V. González-Rodríguez, and L. F. Barral-Losada, "Development of an ultraperformance liquid chromatography method for improved determination of additives in polymeric materials," Journal of Separation Science, vol. 30, no. 15, pp. 2452-2459, 2007.

[5] K. R. Sanjay, N. Kumaresan, K. Akhilender Naidu et al., "Safety evaluation of pigment containing Aspergillus carbonarius biomass in albino rats," Food and Chemical Toxicology, vol. 45, no. 3, pp. 431-439, 2007.

[6] K. Doh-Ura, K. Tamura, Y. Karube, M. Naito, T. Tsuruo, and Y. Kataoka, "Chelating compound, chrysoidine, is more effective in both antiprion activity and brain endothelial permeability than quinacrine," Cellular and Molecular Neurobiology, vol. 27, no. 3, pp. 303-316, 2007.

[7] W. Gui, Y. Xu, L. Shou, G. Zhu, and Y. Ren, "Liquid chromatography-tandem mass spectrometry for the determination of chrysoidine in yellow-fin tuna," Food Chemistry, vol. 122, no. 4, pp. 1230-1234, 2010.

[8] Y. Tonogai, S. Ogawa, Y. Ito, and M. Iwaida, "Actual survey on TLm (median tolerance limit) values of environmental pollutants, especially on amines, nitriles, aromatic nitrogen compounds and artificial dyes," Journal of Toxicological Sciences, vol. 7, no. 3, pp. 193-203, 1982.

[9] I. Surowiec, B. Szostek, and M. Trojanowicz, "HPLC-MS of anthraquinoids, flavonoids, and their degradation products in analysis of natural dyes in archeological objects," Journal of Separation Science, vol. 30, no. 13, pp. 2070-2079, 2007.

[10] S. A. S. Mapari, U. Thrane, and A. S. Meyer, "Fungal polyketide azaphilone pigments as future natural food colorants?" Trends in Biotechnology, vol. 28, no. 6, pp. 300-307, 2010.

[11] T. Reyns, S. Fraselle, D. Laza, and J. Van Loco, "Rapid method for the confirmatory analysis of chrysoidine in aquaculture products by ultra-performance liquid chromatography-tandem mass spectrometry," Biomedical Chromatography, vol. 24, no. 9, pp. 982-989, 2010.

[12] S. J. Ji, Q. H. Zhang, and Y. X. Shen, "Screening for colour developer and optimization of reaction conditions for fast determination of basic orange in foods," Food Science, vol. 31, no. 20, pp. 394-398, 2010.

[13] S. Sun, Y. Wang, W. Yu et al., "Determination of sudan dyes in red wine and fruit juice using ionic liquid-based liquid-liquid microextraction and high-performance liquid chromatography," Journal of Separation Science, vol. 34, no. 14, pp. 1730-1737, 2011. 
[14] C. Li, Y. L. Wu, and J. Z. Shen, "UPLC-ESI-MS/MS analysis of sudan dyes and Para Red in food," Food Additives and Contaminants: Part A Chemistry, Analysis, Control, Exposure and Risk Assessment, vol. 27, no. 9, pp. 1215-1220, 2010.

[15] G. Fang, Y. Wu, X. Dong, C. Liu, S. He, and S. Wang, "Simultaneous determination of banned acid orange dyes and basic orange dyes in foodstuffs by liquid chromatographytandem electrospray ionization mass spectrometry via negative/positive ion switching mode," Journal of Agricultural and Food Chemistry, vol. 61, no. 16, pp. 3834-3841, 2013.

[16] H. Lei, J. Liu, L. Song et al., "Development of a highly sensitive and specific immunoassay for determining chrysoidine, a banned dye, in soybean milk film," Molecules, vol. 16, no. 8, pp. 7043-7057, 2011.

[17] A. P. Abbott, J. C. Barron, K. S. Ryder, and D. Wilson, "Eutecticbased ionic liquids with metal-containing anions and cations," Chemistry - A European Journal, vol. 13, no. 22, pp. 6495-6501, 2007.

[18] Q. Zhang, K. De Oliveira Vigier, S. Royer, and F. Jérôme, "Deep eutectic solvents: Syntheses, properties and applications," Chemical Society Reviews, vol. 41, no. 21, pp. 7108-7146, 2012.

[19] W. Bi, M. Tian, and K. H. Row, "Evaluation of alcoholbased deep eutectic solvent in extraction and determination of flavonoids with response surface methodology optimization," Journal of Chromatography A, vol. 1285, pp. 22-30, 2013.

[20] H. Zhang, B. Tang, and K. H. Row, "A Green Deep Eutectic Solvent-Based Ultrasound-Assisted Method to Extract Astaxanthin from Shrimp Byproducts," Analytical Letters, vol. 47, no. 5, pp. 742-749, 2014.

[21] X. Li, M. Hou, B. Han, X. Wang, and L. Zou, "Solubility of $\mathrm{CO}_{2}$ in a choline chloride + urea eutectic mixture," Jonual of Chemical \& Engineering Data, vol. 53, no. 2, pp. 548-550, 2008.

[22] B. G. Pollet, J.-Y. Hihn, and T. J. Mason, "Sono-electrodeposition (20 and $850 \mathrm{kHz}$ ) of copper in aqueous and deep eutectic solvents," Electrochimica Acta, vol. 53, no. 12, pp. 4248-4256, 2008.

[23] H. G. Morrison, C. C. Sun, and S. Neervannan, "Characterization of thermal behavior of deep eutectic solvents and their potential as drug solubilization vehicles," International Journal of Pharmaceutics, vol. 378, no. 1-2, pp. 136-139, 2009.

[24] K. Shahbaz, F. S. Mjalli, M. A. Hashim, and I. M. AlNashef, "Using deep eutectic solvents based on methyl triphenyl phosphunium bromide for the removal of glycerol from palm-oilbased biodiesel," Energy and Fuels, vol. 25, no. 6, pp. 2671-2678, 2011.

[25] F. S. Oliveira, A. B. Pereiro, L. P. N. Rebelo, and I. M. Marrucho, "Deep eutectic solvents as extraction media for azeotropic mixtures," Green Chemistry, vol. 15, no. 5, pp. 1326-1330, 2013.

[26] K. Pang, Y. Hou, W. Wu, W. Guo, W. Peng, and K. N. Marsh, "Efficient separation of phenols from oils via forming deep eutectic solvents," Green Chemistry, vol. 14, no. 9, pp. 2398-2401, 2012.

[27] Y. Dai, J. Van Spronsen, G.-J. Witkamp, R. Verpoorte, and Y. H. Choi, "Natural deep eutectic solvents as new potential media for green technology," Analytica Chimica Acta, vol. 766, pp. 61-68, 2013. 

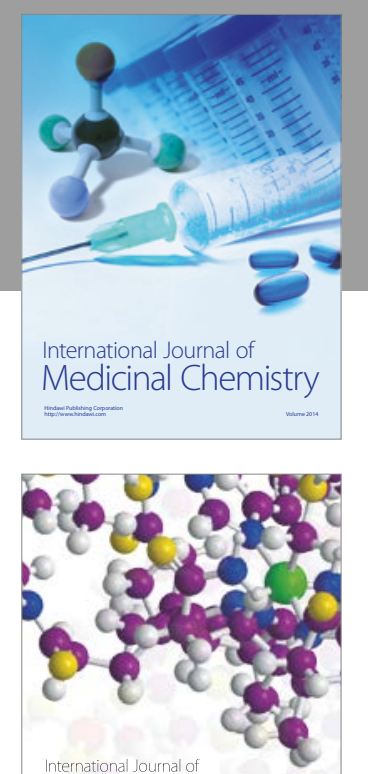

Carbohydrate Chemistry

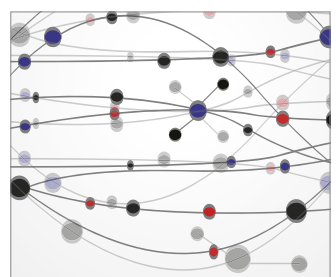

The Scientific World Journal
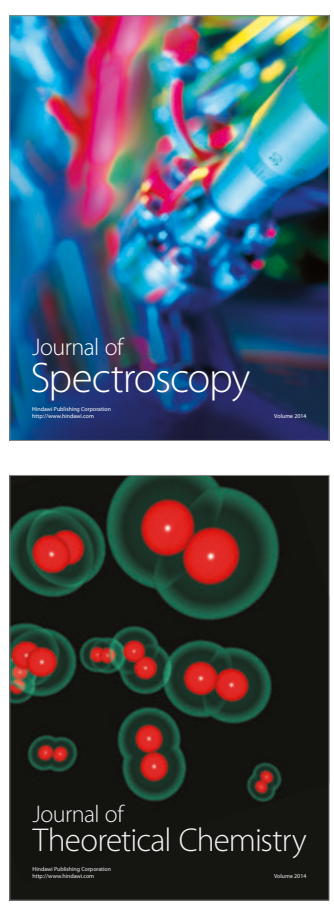
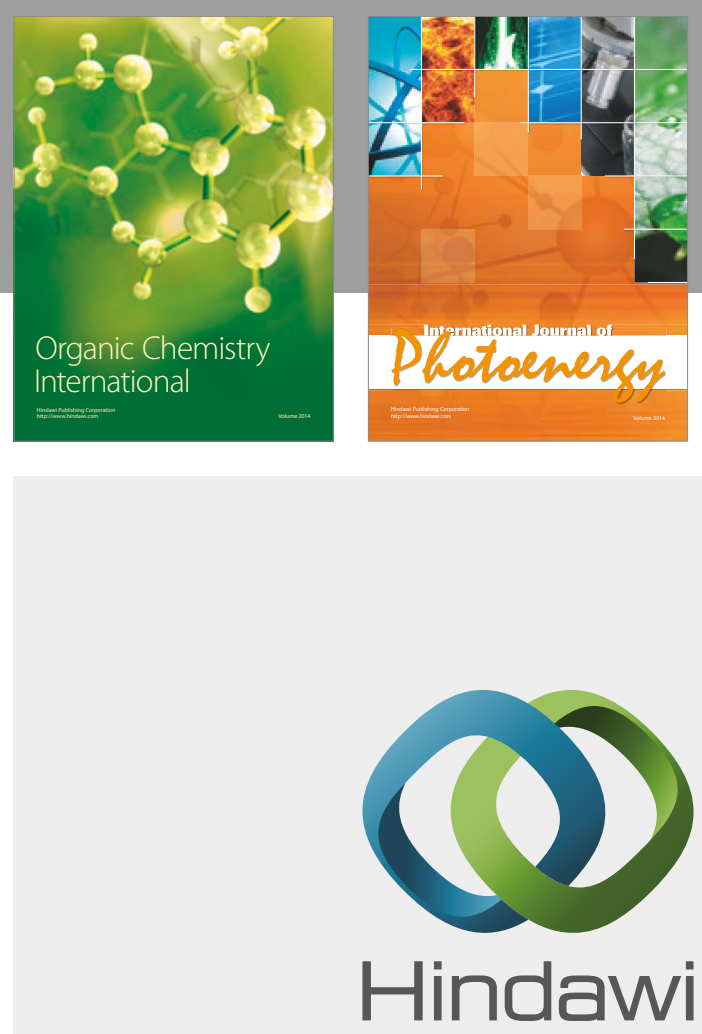

Submit your manuscripts at

https://www.hindawi.com

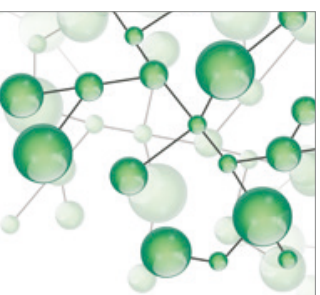

International Journal of

Inorganic Chemistry

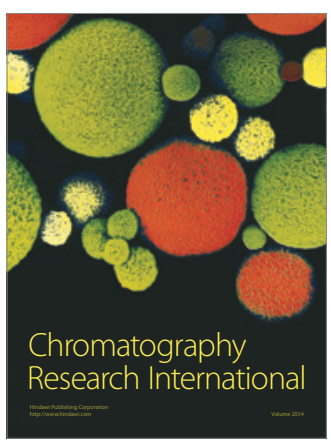

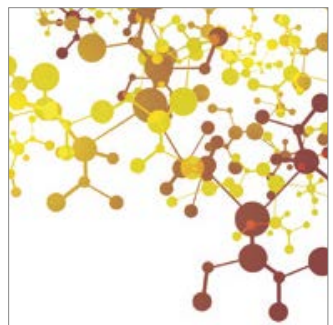

Applied Chemistry
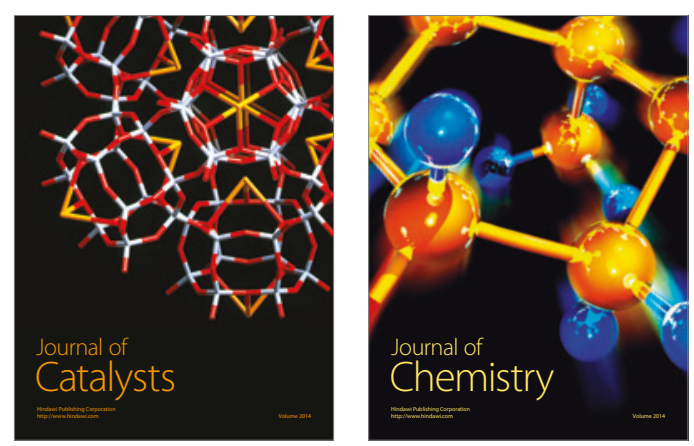
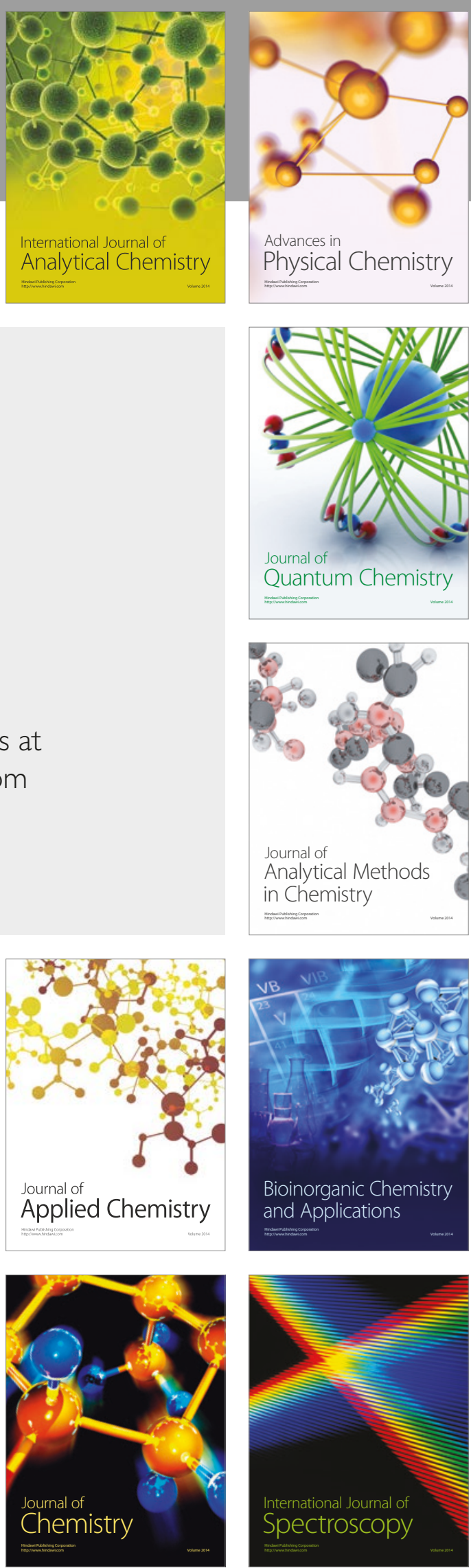